\title{
DOCÊNCIAS-NÔMADE NA EDUCAÇÃO: O QUE NOS FORÇA A PENSAR?
}

\author{
NOMADIC-TEACHING AND EDUCATION: WHAT FORCES OUR THINKING?
}

\author{
Letícia Regina Silva Souza ${ }^{1}$ \\ Ana Carolina Justiniano ${ }^{2}$ \\ Tamili Mardegan da Silva ${ }^{3}$
}

\begin{abstract}
Resumo: Trata-se de um recorte atemporal de pesquisas que apresentam como seus intercessores teóricos Deleuze e Guattari e que estão interessadas nos acontecimentos produzidos pelas docências nos territórios movediços da educação, tendo como um de seus principais objetivos problematizar as composições das formas e dos fluxos que produzem outras docências possíveis. Movimentos que, deslocados pela filosofia da diferença, entrelaçam-se aos pensamentos abertos que provocam e forçam ao exercício de (des)apropriar, (des)continuar e (des)alocar o arcabouço de uma educação que esteve, e ainda está, legitimada nos princípios da padronização, da verdade e da homogeneização do fazer pedagógico, ou seja, de uma ciência moderna, pautada nos ideais cristalizados de uma educação régia. Objetiva, ainda, defender que as docências se realizam com as experiências e com os encontros vivenciados cotidianamente por docentes-discentes, nos diferentes territórios da educação, na efemeridade de uma vida-corpo, que rompe com o instituído. Palavras-chave: Educação; docência; nômade.
\end{abstract}

\begin{abstract}
This research draws on the notion of nomadic-teaching and is grounded on Deleuze and Guattari theorization and focuses on the events produced by the teachers amid moving territories of education. One of the main goals is to problematize the compositions and flows that give birth to other possible ways of teaching. Such movements are displaced by the Philosophy of Difference and intertwined with open thoughts that provoke and force the exercise of (dis) appropriating, (dis) continuing and (dis) locating the framework of an education that has been based on principles such as standardization, truth and homogenization of pedagogical practice, that is to say, based on modern science and its crystallized ideals of education. It also aims at highlighting that teaching takes place throughout daily experiences and encounters teacherstudents go through both in the different territories of education and in the ephemerality of a lifebody. This process, hence, breaks with the instituted forms of education.
\end{abstract}

Keywords: Education; teaching; nomadic.

\section{Palavras iniciais para falar de uma vida}

Nestas variações tão moventes e tão diversas que experimentamos, buscamos falar de uma educação perpassada pelo nomadismo, pelos movimentos que não se permitem ser representados apenas pelo que dizem os especialistas, mas, que são produzidos nos espaços movediços das escolas, pelos atores anônimos de uma vida mais próxima do real. Uma educação que se produz nas relações, nos enlaces de processos, de objetos, de movimentos, de pensamentos e de pessoas também.

Deleuze (2013) fala que o plano da vez é a educação nacional, e isto significa precisamente, a entrega da escola à empresa. O ensino deve produzir bons "empreendedores de si”. Neste sentido, a escola deixa de ser apenas o espaço da educação dos estudantes. Ela passa

\footnotetext{
${ }^{1}$ Universidade Federal do Espirito Santo, Vitória, ES, Brasil.

${ }^{2}$ Universidade Federal do Espirito Santo, Vitória, ES, Brasil.

${ }^{3}$ Universidade Federal do Espirito Santo, Vitória, ES, Brasil.
} 
a envolver também a família, a comunidade. É nesta sociedade que a escola está inserida, onde o ambiente escolar, dessa maneira, não é mais o da reclusão, pois esse modelo está em crise.

O status operante é da dissipação das fronteiras e das trocas flutuantes, ao mesmo passo que os mecanismos de controle operam à enésima potência, trazendo ao regime das escolas: "[...] as formas de controle contínuo, avaliação contínua, e a ação da formação permanente sobre a escola, o abandono correspondente de qualquer pesquisa na Universidade, a introdução da 'empresa' em todos os níveis de escolaridade" (DELEUZE, 2013, p. 229).

Ocupada por um poder que atinge todo o social, nesta sociedade falamos de subjetividades desterritorializadas. Assim, mesmo nessa construção dos padrões de comportamento, observamos a possibilidade de tratarmos das intensidades de uma vida (DELEUZE, 2002a) que se regenera e permite o combate ao poder sobre os corpos. Criação de espaços que permitem a proliferação das vidas.

Pensamentos deleuzeanos que nos forçam a (des)apropriar, a (des)continuar e a (des)alocar o arcabouço de uma educação que esteve, e ainda está, legitimada nos princípios da padronização, da verdade e da homogeneização do pensamento pedagógico, ou seja, de uma ciência moderna-régia pautada nos ideais cristalizados de uma educação clássica. E, por experimentarmos os devirespesquisadora, ${ }^{4}$ é que apostamos politicamente na composição com os intercessores teóricos que nos forçam a pensar uma educação nos interstícios de uma vida que acontece na imanência.

Uma vida é a imanência da imanência, a imanência absoluta: ela é potência completa, beatitude completa. [...] Uma vida está em toda parte, em todos os momentos que este ou aquele sujeito vivo atravessa e que esses objetos vividos medem: vida imanente que transporta os acontecimentos ou singularidades que não fazem mais que se atualizar nos sujeitos e nos objetos. Essa vida indefinida não tem, ela própria, momentos, por mais próximos que estejam uns dos outros, mas apenas entre-tempos, entre-momentos. Ela não sobrevém, nem sucede, mas apresenta a imensidão do tempo vazio no qual vemos o acontecimento ainda por vir e já ocorrido, no absoluto de uma consciência imediata (DELEUZE, 2002a, p. 12-13).

Vidas que são perpassadas por (re)ações/relações cotidianas advindas de múltiplos espaços-tempos e direções que, nos percursos de andarilhar, estão ensaiando outros tantos devires-docência. Ou seja, no intervalar dos acontecimentos, em meio às singularidadesmultiplicidades, tecemos modos outros de produzirmos docências provisórias que, ao habitarmos num espaço nômade e liso, provocamos no pensamento sua própria transmutação na efemeridade da vida, do devir e da docência.

Territorializados por características do modelo da representação e com o comprometimento contínuo do pensamento em busca de "verdades" tidas como universais, no decorrer de toda uma vida territorializada que nós, sujeitos docentes-singulares e impessoais, estamos a viver. Movimentos que nos violentam, impulsionando-nos a desterritorializar os terrenos já habitados e pensar a partir de outras lógicas, reterritorializando de outros modos ainda mais fluidos.

Pertencentes às múltiplas e diferentes redes de modos de produzir docências, destacamos que, a docência que estamos a problematizar, perpassa pelo viés de uma ciência nômade, na tentativa de subverter a ciência régia, no que se refere à educação-pedagogia-escola nos modelos hegemônicos e clássicos de se pensar e fazer educação. É que pensamos numa concepção de docência-nômade, a partir dos modos proliferados pelas próprias docências que

\footnotetext{
${ }^{4}$ Juntar palavras é uma inspiração advinda do campo dos estudos nos/dos/com os cotidianos, no qual os pesquisadores fazem uso deste artifício para produzir sentidos outros às palavras tão carregadas de clichês, buscando não se limitar a uma ou à outra palavra, mas em suas composições.
} 
alimentam a máquina de guerra, esta que "[...] se revela de uma outra espécie, de uma outra natureza e de uma outra origem" (DELEUZE; GUATTARI, 2012a, p. 16).

Atualmente, têm se tornado perceptíveis as ações governamentais ocorridas no âmbito educacional na garantia da assegurar a homogeneização legitimidade pelas verdades da ciência régia. Dentre tantas investidas, as tendenciosas tentativas de forçar a adesão dos sistemas de ensino municipais e estaduais aos pacotes de formações continuadas que são propostos e gerenciados pelos projetos da iniciativa privada, especificamente, pelas empresas do terceiro setor. Sabemos que, em meio a essas imposições, são traçados outros modos de fazer docências, que vazam da superfície corroendo toda lógica determinista e permitindo o suspirar, por meio das docências que são experimentadas nos interstícios de uma vida.

Destacando o que acontece nos cotidianos escolares, ousamos falar de uma educação a partir dos tensionamentos deleuzianos, uma curiosa maneira de conceber o desafio do ensino como um processo que não se trata de transmitir uma informação, ou uma técnica de análise, mas de trabalhar uma matéria em movimento: o pensamento. Não uma escola, mas um movimento. Não a falação, mas um encontro. Não necessariamente um encontro com intelectuais, mas com as coisas, com as obras, com os afectos, com as intensidades, com as aprendizagens. Um deserto atravessado estranhamente por uma conjunção de tribos. Educação nômade, de encontros fortuitos e inevitáveis.

Educações tomadas pelos efeitos dos encontros, capturas e abandonos, repetições cambiantes. Estratégias disruptivas de um cotidiano como multiplicidade, que quer falar de forças estranhas que agem de modo mais aberto e liso, em meio às estratificações e aos clichês que modulam, achatam, aplainam.

\section{Involução: as lógicas podem ser outras}

Ao pesquisarmos com os aportes de pensamentos pautados pela filosofia da diferença, somos movidos e forçados a pensar uma educação que escape das amarras do pensamento dogmático e tradicional, o que seria, para Deleuze e Guattari (1992), um ir em defesa do pensamento em sua potência criadora que, sufocado pela hegemonia do pensamento representacional, pode ser abafado junto aos movimentos das docências-nômade que acontecem na educação, nos entremeios dos pensamentos que experenciam um continuo processo de involução (DELEUZE; PARNET, 1998).

$\mathrm{Na}$ defesa do conceito de um devir que é involutivo na educação é que preferimos nomear de involução os processos de evolução acontece faz entre heterogêneos, sobretudo com a condição de que não se trate de regressão. Encontro e criação:

No devir não há passado, nem futuro, e sequer presente; não há história. Tratase, antes, no devir de involuir: não é nem regredir, nem progredir. Devir é tornar-se cada vez mais sóbrio, cada vez mais simples, tornar-se cada vez mais deserto e, assim, mais povoado. É isso que é difícil de explicar: a que ponto involuir, é evidentemente, o contrário de evoluir, mas também, o contrário de regredir, retornar à infância ou a mundo primitivo. Involuir é ter um andar cada vez mais simples, econômico, sóbrio [...]. Involuir é estar 'entre', no meio, adjacente [...] (DELEUZE; PARNET, 1998, p. 39-40).

Logo, neste contexto afirmamos que a involução é criadora... Que, em outras palavras, "[...] involuir é formar um bloco que corre seguindo sua própria linha, 'entre' os termos postos em jogo, e sob as relações assinaláveis” (DELEUZE; GUATTARI, 2012b, p. 20), considerando a involução como processo de criação e de resistência, desprendendo-se, dessa maneira, das configurações tradicionais que acoplam a esse termo um status negativo. Dito de outro modo, 
nosso objetivo é o de evidenciar práticas de criação de espaços inéditos promovidos pela involução em meio à lógica produtiva contemporânea, em seus mais múltiplos sentidos. Provocações que nos impelem a abdicar da vontade de verdade e nos permitem duvidar um pouco mais das coisas, substituindo o desejo de respostas, por uma vontade de criação.

Partimos do pressuposto conceitual deleuziano de se pensar os acontecimentos ${ }^{5}$ que reverberam o involuir dos devires-docência, ou seja, o devir-ilimitado torna-se o próprio acontecimento, “[...] com todas as reviravoltas que lhe são próprias, do futuro e do passado, do ativo e do passivo, da causa e do efeito" (DELEUZE, 2017, p. 21). Acontecimentos que potencializam as docências-nômade, as quais que podemos denominar de singulares-múltiplas-singulares.

Pensar em docências-nômade, com intercessão do pensamento de uma ciência nômade apresentada por Deleuze e Guattari (2012c, p. 26) é "Bem mais, essa ciência nômade que não para de ser 'barrada', inibida ou proibida pelas exigências e condições da ciência de Estado". Sendo, tal pensamento a experiência de resistência ao presente, fundada na vocação política, em meio a um estilo minoritário de viver, nas problematizações de um pensamento deleuziano que se compõem uma educação para vida, que diante de um cenário educacional atual estamos a experimentar em meio as máquinas de estado que operam com toda força buscando inibir os fluxos da criação.

Minoritário que não tem a ver com grandeza ou pequenez, mas com os devires de uma educação menor, potente e resistente, que é tecida despercebidamente por uma minoria. Minoria representada pelo povo da escola que, quando se cria, é por meios próprios. Deleuze (2013, p. 218) nos traz uma importante contribuição nesta definição da coexistência desses dois mundos no mesmo plano:

As minorias e as maiorias não se distinguem pelo número. Uma minoria pode ser mais numerosa que uma maioria. O que define a maioria é um modelo ao qual é preciso estar conforme [...]. Ao passo que uma minoria não tem modelo, é um devir, um processo. Pode-se dizer que a maioria não é ninguém. Todo mundo, sob um ou outro aspecto, está tomado por um devir minoritário que o arrastaria por caminhos desconhecidos caso consentisse em segui-lo.

A partir disso, percebemos a escola e suas políticas se alteraram naturalmente, de acordo com a sociedade em que estão inseridas. O que está sendo implantado são novos tipos de sanções, de educação, de tratamento. As instituições estão cada vez mais abertas: hospitais, igrejas, domicílios e, evidentemente, as escolas: “[...] a educação será cada vez menos um outro meio fechado, distinto do meio profissional - um outro meio fechado -, mas que os dois desparecerão em favor de [...] um controle contínuo se exercendo sobre o operário-aluno ou o executivo-universitário" (DELEUZE, 2013, p. 220).

Opondo-se ao pensamento de uma educação estática, intencionamos a proposição de um pensamento de fluxo turbilhonar, pois a própria vida em sua efemeridade dos acontecimentos nos coloca "[...] para entrar num campo de celeridade; quando paramos de contemplar o escoamento de um fluxo laminar com direção determinada, e somos arrastados por um fluxo turbilhonar" (DELEUZE; GUATTARI, 2012c, p. 40), que flui e deixar fluir, fugindo dos dogmas instituídos pela educação clássica e produzindo devires-docências-nômades, no intermezzo de um modo deleuziano de pensar o fazer de uma educação.

Desejamos compulsar o pensamento partindo das questões filosóficas da diferença, visto que, para Deleuze e Guattari (1992), pensar é o deslocar-se, é a ruptura, é o atravessamento com as verdades advindas do fora. Definimos o "fora", como um devir de forças que subtraem a história, dando ao pensamento sua tendência inatual e geográfica. Por que, então, se referir a

\footnotetext{
${ }^{5} \mathrm{O}$ acontecimento não é o que acontece (acidente), ele é no que acontece o puro expresso que nos dá sinal e nos espera (DELEUZE, 2017, p. 166).
} 
tal pensamento como intempestivo? Devido à experimentação que entrelaça o ato de pensar, se fazendo antagônica aos pensamentos instituídos pelas verdades absolutas e determinadas pelo contexto sócio-político, a qual somos parte e nele (re)existimos cotidianamente.

Afirmamos que a educação cotidiana é múltipla, carregada de sentidos e nuances, por isso vivemos com o incontrolável, com o caótico, com o imprevisível, mas também com o molar, com o fixo e com o instituído. É uma coisa e outra... Tudo se desfaz num espaço movediço, incerto e inconsistente. Isso diz respeito aos efeitos dos agenciamentos em que nós, pesquisadoras-professoras, não somos mais nós mesmos, mas estamos sempre sendo ajudadas, aspiradas, multiplicadas (DELEUZE; GUATTARI, 1992). Logo, somos muitas, somos únicas, individuais-coletivas. Um plano de composição espinosano em que um corpo afeta outros corpos, ou é afetado por outros corpos: nesse afetar e ser afetado, o que também define um corpo na sua individualidade (DELEUZE, 2002b).

Corpos que, afetados pelos pensamentos deleuzianos, ziguezagueiam e balanceiam nos fluxos das "[...] ciências ambulantes, itinerantes, que consistem em seguir um fluxo num campo de vetores no qual singularidades se distribuem [...]" (DELEUZE; GUATTARI, 2012c, p. 40), em suas próprias histórias, suas crenças e suas vidas, de um ponto ao outro, sem direções, mas com intensidades que pulsam as produções de sentidos outros para uma vida em sua constante imanência.

Pesquisar para além dos padrões estabelecidos e aproximar de uma maneira de pesquisa que estabeleça uma relação de problematização e proliferação, produzindo possíveis efeitosacontecimentos, para um corte no pensamento estático-molar, possibilitando o pensamento movimento-molecular. Afinal, os processos (in)voluntários são constituídos pelas linhas molares e moleculares, pelos espaços lisos e estriados, pelos territórios/desterritórios/reterritórios, pela macro-micro política, isto é, pelas mais diversas linhas que coexistem num fluxo contínuo de se pensar uma docência-nômade.

[...] os nômades sempre me fascinaram, exatamente porque são pessoas que não viajam. Quem viaja são os imigrantes. Há pessoas obrigadas a viajar: os exilados, os imigrantes. Mas estas são viagens das quais não se deve ir, pois são viagens sagradas, são forçadas. Mas os nômades viajam pouco. Ao pé da letra, os nômades ficam imóveis. Todos os especialistas concordam: eles não querem sair, eles se apegam à terra. Mas a terra deles vira deserto e eles se apegam a ele, só podem 'nomadizar' em suas terras. É de tanto querer ficar em suas terras que eles 'nomadizam'. Portanto, podemos dizer que nada é mais imóvel e viaja menos do que um nômade. Eles são nômades porque não querem partir (DELEUZE, 1988, p. 102).

Para tanto, inspirados por Deleuze (1988), somos atravessados pelos pensamentos nômades que são as brechas que provocam os deslocamentos em meio às forças e às ferramentas do aparelho de estado, de uma maneira maquínica-colonial-capitalística (RONILK, 2018) que sequestra os possíveis. Mas, que nos interstícios, resistimos e criamos outras linhas de fugas, para um respirar em busca de nós mesmos. Num devir-pesquisadoras na espreita do pesquisar, mergulharemos nas (in)constâncias de um mar que se faz preciso navegar e fascinar em outras terras como os nômades, os ambulantes e os itinerantes.

Como revide ao regime colonial capitalístico (ROLNIK, 2018) que rouba nossas forças e cafetina as existências, ousamos pensar nos currículos tecidos nas germinações de mundos, nos nomadismos que desafiam qualquer pretensão de enrijecer os movimentos curriculares como a Base Nacional Comum Curricular (BNCC), por exemplo. Assim, a docência nômade diz respeito à construção de novos mundos e ao desmanchamento de outros mundos. Portanto, é eminentemente político por suscitar vidas em processo de expansão. 
Isso está intimamente ligado, também, ao controle estabelecido sobre as informações e, consequentemente, sobre os sujeitos, causando um círculo vicioso e viciante, no qual "[...] os indivíduos são o resultado de uma produção de massa. O indivíduo é serializado, registrado, modelado" (GUATTARI, ROLNIK, 2013, p. 40) pela ordem capitalística. A ordem capitalística, por usa vez,

[...] produz os modos das relações humanas até em suas representações inconscientes: os modos como se trabalha, como se é ensinado, como se ama, como se transa, como se fala, e não para por aí. Ela fabrica a relação com a produção, com a natureza, com os fatos, com o movimento, com o corpo, com a alimentação, com o presente, com o passado e com o futuro - em suma, ela fabrica a relação do homem com o mundo e consigo mesmo. (GUATTARI, ROLNIK, 2013, p. 51).

Vivemos imersos às imagens, aos sons, às mensagens, carregadas de clichês e que podem perturbar os processos de criação quando a comunicação é excessiva, característica nítida da sociedade modular: "Não nos falta comunicação, ao contrário, nós temos comunicação demais, falta-nos criação. Falta-nos resistência ao presente" (DELEUZE; GUATTARI, 2010, p. 130).

Criar é resistir, ressignificar, dar novos sentidos ao que nos é imposto, mesmo quando se trata de um inevitável estado de controle, em que as forças repressivas forçam as pessoas a se exprimirem, quando não se tem grande coisa a dizer (DELEUZE, 2013). Desejamos que a involução seja um território interruptor, no qual a criação encontre bolsões de ar para respirar e resistir em meio ao problema do esvaziamento da linguagem, o empobrecimento da comunicação.

Desta maneira, esta pesquisa é uma aposta em políticas de vida que se efetuam nas alianças e na "[...] vontade de potência positiva, ancorada num movimento para o infinito, para o excesso" (LINS, 2001, p. 108). Movimentos que se criam nas superfícies e modificam os espaços para se afirmarem. Nossa busca é por movimentos curriculares que se fazem no jogo entre sedentaridades nômades e as políticas totalizantes, para problematizar os escapes criados como potentes fontes de criação, por onde a diferença escapa e germina.

Tensionamos, assim, os currículos de uma educação transversalizada pelos devires da involução, cartografando os efeitos disso na produção curricular que acontece cotidiana e desordenadamente nas escolas públicas. De certo, alguns consensos existem e fazem parte do histórico dos estudos do campo do currículo, principalmente em sua origem, na qual referiase especialmente à organização dos conteúdos e dos objetivos agrupados em disciplinas, gerando resultados de uma grade curricular monolítica, sendo que essa descrição pode ser observada até hoje em muitos discursos.

Entretanto, apesar do consenso percebido que discursa na defesa de que o currículo é a seleção do que deve ser ensinado, com o avanço das pesquisas na área e também com as vivências escolares, foi possível perceber que o mesmo currículo padronizado não dá conta de todos contextos e sujeitos nos mais diversos cotidianos escolares.

Desta maneira, percebemos o currículo, como uma poderosa prática discursiva, carregada de marcas sociais e culturais e que está estritamente ligada ao contexto histórico de um povo. Nele estão presentes as lutas da marcação de território, pois ele próprio é um campo de disputas culturais. Pensar no seu poder é avaliar o controle social e a utilidade que possui, principalmente se nos perguntarmos a quem e para quem ele serve. Além disso, é preciso pensar sobre a forma como lidamos com o currículo e o seu funcionamento, para consideramos suas possibilidades de tessitura em meio aos devires de involução.

É preciso aguçar a percepção quanto à importância do pensamento e da ação política do currículo, em que ocorre tudo ao mesmo tempo (FERRAÇO, 2007), na existência do que é prescrito, ao mesmo passo em que existem, por dentro dele, as redes de saberesfazeres produzidas por docentes 
e discentes. É no caos das ações (des)ordenadas, que esse emaranhado de acontecimentos vai dando vida às práticas-políticas que pulsam nas escolas e que produzem efeitos de aprendizagens. Dito de outro modo, as práticas cotidianas também são políticas curriculares de educação.

Partindo de uma conceituação dos currículos e algumas configurações que apostamos, percebemos que a política educacional atual exige um enfrentamento daquilo que nos oprime e nos sujeita para instaurar novas experimentações. Vemos na docência nômade a chance da constituição de novos espaços que ampliam nosso ser-estar, fazem um novo campo se abrir para outras sensibilidades. Nas dobras que insurgem desse devir-nômade da docência, encontramos saídas diante de um currículo que as políticas maiores, como a BNCC, não conhecem. Na dobra, instaura-se um ser-estar nômade, como pensado por Deleuze:

[...] o nômade não é forçosamente alguém que se movimenta: existem viagens num mesmo lugar, viagens em intensidade, e mesmo historicamente os nômades não são aqueles que se mudam à maneira dos migrantes; ao contrário, são aqueles que não mudam, e põem-se a nomadizar para permanecerem no mesmo lugar, escapando dos códigos (DELEUZE, 1985, p. 66).

A docência nômade, se rabisca nos currículos como escapes para respirar, como uma necessidade de aliançar-se ao corpo do mar:

É tenso! Tem coisa que dá vontade de você.... Não... Todo dia eu acordo e dá vontade de falar assim: 'Tomara que não tenha nenhum problema, que não tenha nenhum problema, tomara seja tudo tranquilo'. Mas se você 'tá' envolvida naquilo e você tem que dar conta, mesmo que tudo esteja contra você. Porque nada, tá... Muitas vezes nada tá a seu favor. A gente aqui na escola tem um grupo legal. Fora daqui é difícil, porque a gente pede a Deus pra não ter problema a gente tenta, mas às vezes a escola é o único lugar que eles têm. A gente não pode deixar pra lá... eu não posso simplesmente fingir que eu não vejo, às vezes ali é o único lugar de segurança deles.

Algumas vezes eles saem só para dar uma volta, respirar e vão parar na minha sala. Desde que comecei na coordenação, quando eles chegam na minha sala, eu paro pra escutar, eu tento me envolver com eles. Como eu gosto muito de ler, eu gosto do "Game of Thrones", eu pensei em trazer uns livros pra minha sala. Aí eles olham, perguntam, a gente conversa... e eu tenho emprestado livros pra eles. Eu não sou bibliotecária, mas eu acho que a coordenação pode funcionar de outra forma. E eles saem da sala, voltam e tenho vários livros com eles.

Essa coisa de você 'tá' com ensino e você não se envolver afetivamente não rola... Tem uma aluna com depressão, têm muitos alunos com depressão. Aí começamos a conversar e com a ajuda da escola e dos terceiros anos pensamos num festival de afetos. A gente viu que progrediu, não vou falar que ela deu certo, porque é muito difícil dizer o que é uma pessoa dar certo, mas essa menina, ela tá aprendendo a fazer bolo e tá vendendo no Instagram, ela 'tava' num momento de depressão forte, em algum momento a escola teve uma ajuda ali... (Conversações com uma Coordenadora de turno de uma Escola Estadual - 2020).

Escapar dos códigos disciplinares em conversas sobre o Game of Thrones. No vai e vem de livros, nascem imprevisibilidades, algo acontece e o movimento da dobra cria um território de relações distintas, onde se incorporam os possíveis, porque a dobra permite habitar o limite 
do que somos e nos coloca numa linha instável, a linha do fora ${ }^{6}$ cujos contornos se diluem no contato com o desconhecido. São nomadismos que, na dobra, abrem frestas nos limiares, bifurcando em um contexto em que vemos a vida jovem sufocada. Formam-se, então, núpcias, zonas de vizinhança como bolhas, bolsões de vida.

\section{Conclusões para iniciar novas conversas}

A aposta na afetividade como um tipo de resistência, que desliza por entre rochedos e instaura virtualidades que não comportam medidas, nos faz acreditar que a educação também se dá na imanência, em uma vida. Composições e redistribuições de forças e afetos que denotam novos possíveis, reinventando vidas severinas feitas de virtualidades, acontecimentos e singularidades. (DELEUZE, 2002a).

Nesse sentido, o virtual "[...] não é algo que falta à realidade, mas que se envolve num processo de atualização" (DELEUZE, 2013), onde surgem os acoplamentos e devires imperceptíveis ${ }^{7}$ desse coletivo escolar, como diz a professora:

Chega uma hora que a gente vê que tem que parar a escola para reforçar o valor à vida. Eles escolheram o que fazer: ikebana, pra eles saberem que o contato com a natureza cura. Tentamos de tudo um pouco, ficamos com medo do que o pastor ia falar, mas ele começou falando que Deus não cura depressão. Foi um alívio (Conversações com uma Coordenadora de turno de uma Escola Estadual - 2020).

Dobrar, vazar outros modos de existência [...]. Pensamos os processos de subjetivação como política que renuncia a esquemas de opressão, de libertação, de identidade. Nesses movimentos curriculares, a dimensão política da docência-nômade traça linhas em que os currículos oficiais perdem as formas, rompem segmentos e desfiguram as prescrições para gritar por uma vida, num plano de consistência. Deleuze (2002c) diz que esse plano é onde estão as hecceidades, acontecimentos, transformações incorporais.

Nesse plano de consistência se inscrevem: as hecceidades, acontecimentos, transformações incorporais apreendidas por si mesmas; as essências nômades ou vagas, e contudo rigorosas; os continuums de intensidade ou variações contínuas, que extravasam as constantes e as variáveis; os devires, que não possuem termo nem sujeito, mas arrastam um e outro a zonas de vizinhança ou de indecidibilidade; os espaços lisos, que se compõem através do espaço estriado (DELEUZE, GUATTARI, 2012c, p. 222).

Planos que mediante as produções das intensidades de uma vida escapam dos estratos, atravessam agenciamentos e traçam uma linha abstrata sem formas e sem contornos, mas com dobras entre o instituído, o molar, o estriado, o já dado, à espreita dos encontros, dos afetos, devires que pudessem produzir seus modos de docências em suas virtualidades.

\footnotetext{
${ }^{6} \mathrm{O}$ fora é composto por relações de força que provocam mudanças em uma dada estrutura configurada, com outras relações e novas configurações: “[...] um lado de fora mais longínquo que todo o mundo exterior e mesmo de toda forma de exterioridade, portanto infinitamente mais próximo" (DELEUZE, 2005, p. 93).

${ }^{7} \mathrm{O}$ devir-imperceptível é o "[...] puro plano de imanência, de univocidade, de composição, onde tudo é dado, onde dançam elementos e materiais não formados que só se distinguem pela velocidade, e que entram nesse ou naquele agenciamento individuado de acordo com suas conexões, suas relações e movimentos. Plano fixo da vida, onde tudo mexe, atrasa ou se precipita [...]" (DELEUZE; GUATTARI, 2012b, p. 45).
} 
Assim, “[...] o nomadismo como movimento (inclusive no mesmo lugar, ande, não parede de andar, viagem imóvel, dessubjetivação)" (DELEUZE, GUATTARI, 2012a, p. 25). Na tensão entre instituído e instituinte. Mais uma vez, frisamos que a educação e a pesquisa se valem desta intercessão molar-molecular. Uma composição de forças e não uma hierarquia, um nomadismo de pesquisa e suas potências variadas de criação, um acompanhamento do traçado de um plano repleto de linhas não só verticais ou horizontais, mas também transversais.

As virtualidades que se efetuam nos excessos da dobra, suas variações, metamorfoses e variabilidade, esse devir-intenso é necessário para traçar uma estratégia para impedir os processos de escamoteamento da vida. Esse dobrar, desdobrar e redobrar é movimento vital, não apenas porque os processos de apagamento de vidas são continuamente penetrados pelo poder, mas porque os currículos são assentados dentro das estruturas fixas e da segurança conveniente da unidade, o que pode, em tese, apresentar-se como um obstáculo que impede cruzar a multiplicidade e impossibilita a prolongação de suas linhas e a produção de novidade (DELEUZE; GUATTARI, 2012a).

A proposta de desestruturar as lógicas é captar a possibilidade de uma educação involutiva que aluda à magnitude desses territórios imanentes, nas suas reinvenções cotidianas e nos seus infinitivos modos de vida, de linhas de todas as intensidades, molares e moleculares, ao mesmo tempo, no qual se encontram condições de uma vida mais possível de ser vivida e menos arrastada pelos padrões. Essa conversa final é um reinício, para dizermos que apostamos que o conhecimento não é apartado da vida; é a própria vida que abastece as ações complexas que emergem nos cotidianos escolares. Se falamos de vida, falamos de complexidade e, se o cotidiano da escola pode ser tomado como um conjunto de acontecimentos repletos de vida, nunca poderá se exercer o absoluto controle sobre isso.

\section{Referências}

DELEUZE, Gilles. A imanência: uma vida. Educação e realidade, Porto Alegre, v. 2, n. 27, p. 10-18, jul./dez. 2002a.

DELEUZE, Gilles. Conversações. Tradução de Peter Pál Pelbart. São Paulo: Ed. 34, 2013.

DELEUZE, Gilles. Espinosa: filosofia prática. São Paulo: Escuta, 2002b.

DELEUZE, Gilles. Foucault. 1. ed. São Paulo: Brasiliense, 2005.

DELEUZE, Gilles. Lógica do sentido. Tradução de Luiz Roberto Salinas Fontes. São Paulo: Perspectiva, 2017.

DELEUZE, Gilles. O abecedário de Gilles Deleuze. Entrevista a Claire Parnet. Tradução de Tomaz Tadeu da Silva, 1988. Disponível em: http://escolanomade.org/wp-content/downloads/deleuze-oabecedario.pdf. Acesso em: 20 set. 2020.

DELEUZE, Gilles. O Método da Dramatização 1859-1941. In: DELEUZE, Gilles. A ilha deserta e outros textos. São Paulo: Editora Iluminuras, 2002c. p. 112-140.

DELEUZE, Gilles. Pensamento nômade. In: Nietzsche hoje? Colóquio de Cerisy. Organização e revisão técnica Scarlett Marton. Tradução Milton Nascimento e Sônia Salzstein Goldberg. São Paulo: Brasiliense, 1985. 
DELEUZE, Gilles; GUATTARI, Félix. Mil platôs: capitalismo e esquizofrenia. v. 3. São Paulo: Ed. 34, 2012a.

DELEUZE, Gilles; GUATTARI, Félix. Mil platôs: capitalismo e esquizofrenia. v. 4. São Paulo: Ed. 34, $2012 b$.

DELEUZE, Gilles; GUATTARI, Félix. Mil platôs: capitalismo e esquizofrenia. v. 5. São Paulo: Ed. 34, 2012c.

DELEUZE, Gilles; GUATTARI, Félix. O que é filosofia? Rio de Janeiro: Editora 34, 1992.

DELEUZE, Gilles; PARNET, Claire. Diálogos. São Paulo: Escuta, 1998.

GUATTARI, Félix; ROLNIK, Suely. Micropolítica: cartografias do desejo. 12. ed., 4. reimp. (2017). Petrópolis: Vozes, 2013.

FERRAÇO, Carlos Eduardo. Pesquisa com o cotidiano. Revista Educação e Sociedade, Campinas, v. 28, n. 98, p. 73-95, jan./abr., 2007.

LINS, Daniel. Sujeitos e devires: o corpo-drogado. In: LINS, Daniel (Org.). Nietzsche e Deleuze: pensamento nômade. Rio de Janeiro: Relume Dumará; Fortaleza, CE: Secretaria da Cultura e Desporto do Estado, 2001.

ROLNIK, Suely. Esferas da insurreição: notas para uma vida não cafetinada. São Paulo: n-1 Edições, 2018.

\section{Sobre as autoras}

Letícia Regina Silva Souza é Doutoranda em Educação pelo Programa de Pós-Graduação em Educação da Universidade Federal do Espírito Santo (PPGE/CE/Ufes) na Linha de Docência, Currículo e Processos Culturais. Mestra em Educação pelo Programa de Pós-Graduação em Educação da Universidade Federal do Espirito Santo (PPGE/ CE/ Ufes). Especialista em Psicopedagogia pela Unigranrio. Licenciada em Pedagogia pela Universidade São Camilo. Integrante do Grupo de Pesquisa "Currículos, Cotidianos, Culturas e Redes de Conhecimentos", coordenado pelo professor Carlos Eduardo Ferraço. É professora estatutária da educação básica da Rede Municipal de Ensino de Guarapari.

E-mail: le.reginna@gmail.com.

Ana Carolina Justiniano é Doutoranda em Educação pelo Programa de Pós-Graduação em Educação da Universidade Federal do Espírito Santo (PPGE/CE/Ufes) na Linha de Docência, Currículo e Processos Culturais. Mestra em Linguística Aplicada pelo Programa de PósGraduação em Estudos Linguísticos da Universidade Federal de Minas Gerais (POSLIN/ FALE/ UFMG). Especialista em Tradução pela UFMG. Licenciada em Letras-Inglês pela Ufes. Integrante do Grupo de Pesquisa "Currículos, Cotidianos, Culturas e Redes de Conhecimentos", coordenado pelo professor Carlos Eduardo Ferraço. É professora estatutária da Rede Estadual de Ensino do Espírito Santo no ensino médio.

E-mail: anac.justiniano@gmail.com. 
Tamili Mardegan da Silva é Doutoranda em Educação pelo Programa de Pós-Graduação em Educação da Universidade Federal do Espírito Santo (PPGE/CE/Ufes) na Linha de Docência, Currículo e Processos Culturais. Mestra em Educação pelo Programa de Pós-Graduação em Educação da Universidade Federal do Espírito Santo (PPGE/CE/Ufes). Especialista em Informática na Educação e em Alfabetização e Letramento. Licenciada em Pedagogia. Integrante do Grupo de Pesquisa "Currículos, Cotidianos, Culturas e Redes de Conhecimentos", coordenado pelo professor Carlos Eduardo Ferraço. É professora estatutária da Rede Municipal de Ensino de Guarapari na Educação Infantil e nos Anos Iniciais do Ensino Fundamental e, desde 2015, atua na Secretaria da Educação de Guarapari (Semed).

E-mail: tamilimardegan@hotmail.com. 